\title{
CORRELATION BETWEEN ENDOSCOPIC AND HISTOPATHOLOGICAL FINDINGS IN GASTRIC LESIONS
}

Poudel A. , Regmi S. ${ }^{2}$, Poudel S. ${ }^{2}$, Joshi P. ${ }^{3}$

\section{ABSTRACT}

INTRODUCTION: Stomach is an important site for wide variety of lesions which include congenital, inflammatory and neoplastic conditions. Helicobacter pylori(H. pylori) has been implicated in varied range of gastric lesions including Gastritis, Peptic Ulcer (PU), Gastric Adenocarcinoma and Gastric Lymphoma.

MATERIALAND METHODS: A total of 43 gastric biopsies were studied retrospectively over a period of 5 months from March to July 2013 at Department of Pathology, Universal College of Medical Sciences Teaching Hospital, Bhairahawa.

RESULTS: Out of these 43 cases, $29(67.4 \%)$ were male and $14(32.6 \%)$ were female with a male to female ratio of $2.07: 1$. According to the endoscopic findings, out of 43 cases, 25 (58.1\%) cases had Gastritis, 5 (11.63\%) had Peptic Ulcer, 4 (9.30\%) had gastric Carcinoma, 4 (9.30\%) had Chronic Gastritis (CG) with Atrophy, 3 (6.97\%) had Erosive Gastritis and 2 $(4.7 \%)$ had normal mucosa. The correlation of endoscopic and histopathological diagnosis of these gastric lesions was $34.88 \%$.

CONCLUSION: It was observed that endoscopic diagnoses of gastric lesions poorly correlated with those of histopathological diagnoses. H. pylori has a high prevalence in our region and is mostly associated with Intestinal Metaplasia (IM), CG and Atrophic Gastritis (AG).

KEYWORDS: Endoscopy, Gastric Biopsy, Chronic Gastritis, Atrophic Gastritis, Intestinal Metaplasia, Helicobacter pylori.

1. Lecturer, Consultant Pathologist, Lumbini Medical College Teaching Hospital, Pravas, Palpa, Nepal

2. Post Graduate Resident, Department of Pathology, Universal College of Medical Sciences \& Teaching Hospital, Bhairahawa, Nepal

3. Assistant Professor, Consultant, Department of Surgery, Universal College of Medical Sciences \& Teaching Hospital, Bhairahawa, Nepal

For correspondence

Dr. Anuj Poudel, M.D.,

Lecturer,

Lumbini Medical College Teaching Hospital,

Pravas, Palpa, Nepal

Email: dranuj2002@yahoo.co.in 


\section{INTRODUCTION}

The advent of fibre optic endoscopy in recent year has enormously extended the diagnostic possibilities in gastroenterology.

Endoscopic appearances may be valuable in diagnosis but more accurate and detailed information results from histological examination of mucosal biopsy specimens ${ }^{1}$. Over the years it has been realized that the endoscopic appearances are highly suggestive but are not pathognomic and they need histological confirmation. In majority of the conditions histologicaldiagnosis is corroborative and hence for the final diagnosis a good dialogue between clinician, endoscopist, radiologist and pathologist is required ${ }^{2-3}$.

After the discovery of $H$. pylori by Marshall and Warren in 1983 by using Warthin Starry Silver stain ${ }^{4}$, the etiological understanding of $\mathrm{CG}$ and associated lesions have been revolutionized. $H$. pylori has been implicated in varied range of gastric lesions including Gastritis, PU, Gastric Adenocarcinoma and gastric mucosa-associated lymphoid tissue Lymphoma ${ }^{5}$. Usually, the bacteria are easily seen on well-differentiated Haematoxylin and Eosin (H\&E) sections, and it is not necessary to use Giemsa, modified Steiner, or Leung ${ }^{6}$ stains for routine diagnosis ${ }^{7}$. The organisms are slender, curved spirals in the superficial mucous layer, where they tend to be attached to the epithelium at the site of intercellular junctions. Occasionally, following treatment with proton pump inhibitory drugs, $H$. pylori can be present in the stomach as coccoid forms. ${ }^{8}$

This study tends to correlate the histomorphological pattern of gastric mucosal biopsy with distribution of gastric lesions according to age and sex with their relation to $H$. pylori.

\section{MATERIAL AND METHODS}

A total number of 43 gastric biopsies received at Department of Pathology, Universal College of Medical Sciences from the month of March to July were studied retrospectively. Patients suspected for any gastric lesions were taken up for endoscopy and biopsy was taken wherever required. Endoscopies were done using a flexible fibre optic Endoscope. The lesions were noted on gross visualization during endoscopy. Each biopsy obtained from the stomach was put into a small labelled bottle containing $10 \%$ neutral formalin and sent to the department of pathology, UCMS. Those specimens were processed and embedded in paraffin wax and were cut into sections of 5 micrometre thickness. All the slides were stained with H\&E and with Giemsa stain whenever required. All the sections were reported by a consultant pathologist and reviewed by another consultant pathologist. All the statistical analysis was done using SPSS 16.0.

\section{RESULTS}

A total of 43 gastric biopsies were studied retrospectively over a period of 5 months from March to July 2013. Out of these 43 cases, $29(67.4 \%)$ were male and $14(32.6 \%)$ were female with a male to female ratio of 2.07:1. The age range of patients was from 21 years to 96 years with a mean age of 52.52 years. The age and sex distribution of the study is shown in Table 1.

Table 1: Age and Sex distribution of study group

\begin{tabular}{|l|c|c|l|}
\hline \multirow{2}{*}{$\begin{array}{l}\text { Age } \\
\text { Group }\end{array}$} & \multicolumn{2}{|c|}{ Sex of the patient } & \multirow{2}{*}{ Total } \\
\cline { 2 - 3 } & Male & Female & \\
\hline $21-30$ & 2 & 3 & $5(11.63 \%)$ \\
\hline $31-40$ & 3 & 4 & $7(16.27)$ \\
\hline $41-50$ & 4 & 4 & $8(18.61 \%)$ \\
\hline $51-60$ & 7 & 1 & $8(18.61 \%)$ \\
\hline $61-70$ & 7 & 2 & $9(20.93 \%)$ \\
\hline$>71$ & 6 & 0 & $6(13.95 \%)$ \\
\hline
\end{tabular}

Endoscopically diagnosed different gastric lesions with their male to female ratio is shown in Table II. The highest number of patients were with Gastritis followed by PU, erosion, carcinoma and normal study.

Table 2: Age and sex distribution and various endoscopic diagnosis

\begin{tabular}{|l|l|l|l|}
\hline \multirow{2}{*}{$\begin{array}{l}\text { Endoscopic } \\
\text { Diagnosis }\end{array}$} & \multicolumn{2}{|l|}{ Sex of the patient } & \multirow{2}{*}{ Total } \\
\cline { 2 - 3 } & Male & Female & \\
\hline Normal & 0 & 2 & $2(4.7 \%)$ \\
\hline Gastritis & 16 & 9 & $25(58.1 \%)$ \\
\hline $\begin{array}{l}\text { Atrophic } \\
\text { Gastritis }\end{array}$ & 4 & 0 & $4(9.30 \%)$ \\
\hline $\begin{array}{l}\text { Erosive } \\
\text { Gastritis }\end{array}$ & 2 & 1 & $3(6.97 \%)$ \\
\hline Peptic Ulcer & 3 & 2 & $5(11.63 \%)$ \\
\hline Carcinoma & 4 & 0 & $4(9.30 \%)$ \\
\hline
\end{tabular}


Distribution of gastric lesions in different age groups is shown in Table 3. The peak age of incidence of Gastritis was found in the fourth decade and those of PU and Gastric Carcinoma were found in the sixth decade.

Table 3: Distribution of gastric lesions as per age group

\begin{tabular}{|l|c|c|c|c|c|c|c|}
\hline \multirow{2}{*}{ Age Group } & \multicolumn{6}{|c|}{ Endoscopic Diagnosis } & \multirow{2}{*}{ Total } \\
\cline { 2 - 8 } & Normal & Gastritis & AG & EG & PU & Ca & \\
\hline $\mathbf{2 1 - 3 0}$ & 1 & 4 & 0 & 0 & 0 & 0 & 5 \\
\hline $\mathbf{3 1 - 4 0}$ & 1 & 5 & 0 & 1 & 0 & 0 & 7 \\
\hline $\mathbf{4 1 - 5 0}$ & 0 & 6 & 0 & 1 & 1 & 0 & 8 \\
\hline $\mathbf{5 1 - 6 0}$ & 0 & 5 & 1 & 0 & 1 & 1 & 8 \\
\hline $\mathbf{6 1 - 7 0}$ & 0 & 1 & 1 & 1 & 3 & 3 & 9 \\
\hline$>71$ & 0 & 4 & 2 & 0 & 0 & 0 & 6 \\
\hline Total & 2 & 25 & 4 & 3 & 5 & 4 & 43 \\
\hline $\boldsymbol{A G}$-Atrophic Gastritis, $\boldsymbol{E} \boldsymbol{G}$-Erosive Gastritis, $\boldsymbol{P U}$-Peptic Ulcer, $\boldsymbol{C a}$-Carcinoma \\
\hline
\end{tabular}

The correlation between endoscopic findings with histological findings is shown in Table 4 . Twenty five out of 43 cases were diagnosed as Gastritis on endoscopy. Of these, 10 were CG, 9 had IM, 4 has AG and 2 had signs of activity histologically. Out of 4 cases of Erosive Gastritis, none were found to have erosion histologically. Among 5 cases of endoscopically diagnosed AG, only 1 case showed atrophic changes on biopsy. Four cases diagnosed endoscopically as PU were mostly diagnosed as CG with IM (3 cases). However, all 4 of the endoscopically suspected Carcinoma correlated histologically as Adenocarcinoma.

Table 4: Correlation between endoscopic and histopathological diagnosis

\begin{tabular}{|c|c|c|c|c|c|c|c|c|c|}
\hline \multirow{2}{*}{$\begin{array}{l}\text { Endoscopic } \\
\text { Diagnosis }\end{array}$} & \multicolumn{8}{|c|}{ Histopathological Diagnosis } & \multirow[t]{2}{*}{ Total } \\
\hline & $\mathrm{CG}$ & $\begin{array}{c}\mathrm{CG}+ \\
\mathrm{IM}\end{array}$ & $\begin{array}{c}\mathrm{CG}+ \\
\text { Activity }\end{array}$ & $\begin{array}{c}\mathrm{CG}+ \\
\mathrm{AG}\end{array}$ & $\begin{array}{c}\mathrm{CG}+ \\
\text { Activity + } \\
\mathrm{AG}+\mathrm{IM}\end{array}$ & $\begin{array}{c}\mathrm{CG}+ \\
\text { Activity }+ \\
\text { IM }\end{array}$ & $\begin{array}{l}\text { Dyspl } \\
\text { asia }\end{array}$ & $\begin{array}{c}\text { Carcino } \\
\mathrm{ma}\end{array}$ & \\
\hline Normal Study & 1 & 1 & 0 & 0 & 0 & 0 & 0 & 0 & 2 \\
\hline Gastritis & 10 & 9 & 2 & 4 & 0 & 0 & 0 & 0 & 25 \\
\hline $\begin{array}{l}\text { Erosive } \\
\text { Gastritis }\end{array}$ & 1 & 1 & 1 & 0 & 0 & 0 & 0 & 0 & 3 \\
\hline $\begin{array}{l}\text { Atrophic } \\
\text { Gastritis }\end{array}$ & 1 & 1 & 0 & 1 & 0 & 1 & 0 & 0 & 4 \\
\hline Peptic Ulcer & 0 & 3 & 0 & 0 & 1 & 0 & 1 & 0 & 5 \\
\hline Carcinoma & 0 & 0 & 0 & 0 & 0 & 0 & 0 & 4 & 4 \\
\hline Total & 13 & 15 & 3 & 5 & 1 & 1 & 1 & 4 & 43 \\
\hline
\end{tabular}

H. pylori was detected in $18(41.9 \%)$ cases, which was mostly present in cases with CG with IM (55.56\%) but also with CG (22.22\%), CG with AG (16.67\%) and CG with Activity with IM (5.55\%). 


\section{DISCUSSION}

According to the endoscopic findings, out of 43 cases, 25 (58.1\%) cases had Gastritis, 5 (11.63\%) had PU, 4 (9.30\%) had Gastric Carcinoma, 4 (9.30\%) had CG with AG, 3 (6.97\%) had Erosive Gastritis and $2(4.7 \%)$ had normal mucosa. The correlation of endoscopic and histopathological diagnosis of these gastric lesions was $34.88 \%$.Of the 25 cases diagnosed as Gastritis on endoscopy, only 10 were diagnosed histologically as CG, 9 had CG with IM (Fig. I), 4 had CG with AG and 2 had CG with activity. Only $40 \%$ of the cases diagnosed endoscopically as CG correlated with the histopathological diagnosis. This finding is similar to that of study of Levy N. ET $\mathrm{Al}^{9}$. Their study showed $50 \%$ correlation between endoscopically and histopathologically diagnosed CG and emphasized that endoscopy alone should not be relied upon in the diagnosis of gastritis.

Among 5 cases diagnosed as PU on endoscopy, 3 had CG with IM, 1 had dysplasia and 1 had CG with IM with activity. All 4 cases diagnosed endoscopically as Gastric Carcinoma correlated histologically as Gastric Adenocarcinoma (Fig. II). This correlation is supported by the study of Hecker etal. ${ }^{10}$ They recommended endoscopy and biopsy as valuable diagnostic procedures in the investigation of patients suspected of having gastric carcinoma. Used together they can eliminate the necessity for diagnostic laparotomy.

H. pylori was present in 18 cases and was most prevalent with IM (55.56\%). Four cases of CG, 3 cases of CG with GA and 1 case of CG with IM with activity were associated with $H$. pylori.According to Kim N. ET. Al, H. pylori infection is the most important risk factor of IM and AG, which support the findings of our study. H. pylori first causes non-atrophic gastritis which may evolve to AG and IM and finally to dysplasia and Adenocarcinoma. AG and IM are premalignant gastric lesions and endoscopic diagnosis of these premalignant lesions could be helpful to describe a group at high risk for Gastric Cancer. ${ }^{11-12}$

Out of 6 cases which were thought to have H. pylori associated mucosal changes on endoscopy, only 1 was positive for $\mathrm{H}$. pylori on biopsy. Moreover, out of 20 cases thought to be spared of $H$. pylori associated endoscopic mucosal changes, 17 cases were found to be positive. As stated by Calabrese ET. Al., mucosal nodularity showed the highest positive predictive value in detecting the $H$. pylori presence. The single endoscopic features are poorly correlated with histologic changes and H. pylori status ${ }^{13}$. Except for the absence of rugae and visible vessels in the gastric corpus, macroscopic features as observed during gastroscopy are of very limited value in the evaluation of whether or not gastritis or H. pylori infection are present.And, it must be emphasized that the diagnosis of gastritis should be based on histological examination of gastric mucosa. ${ }^{14}$

\author{
Figure 1: H\&E section showing Intestinal Metaplasia in \\ the gastric biopsy. (X100)
}

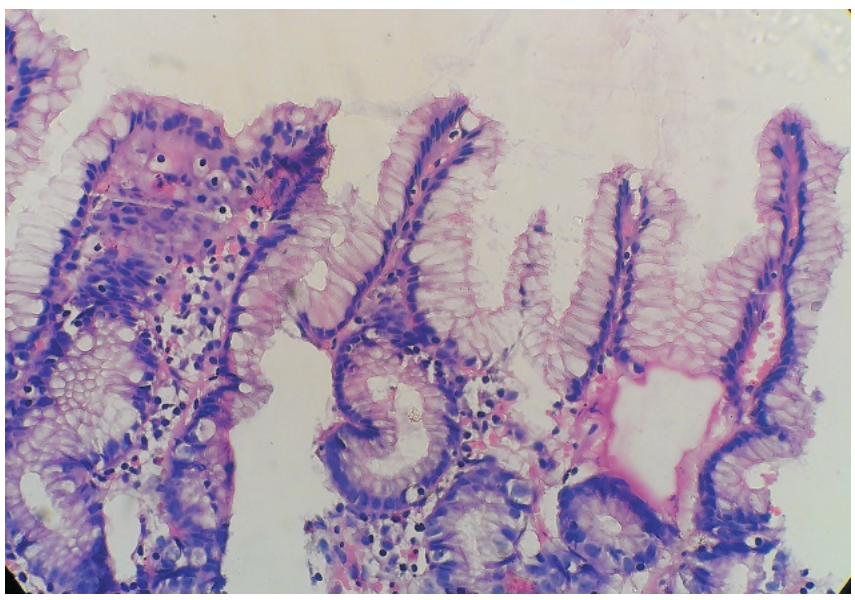

Figure 2: H\&E Section showing Moderately Differentiated Adenocarcinoma in the gastric biopsy. (X100)

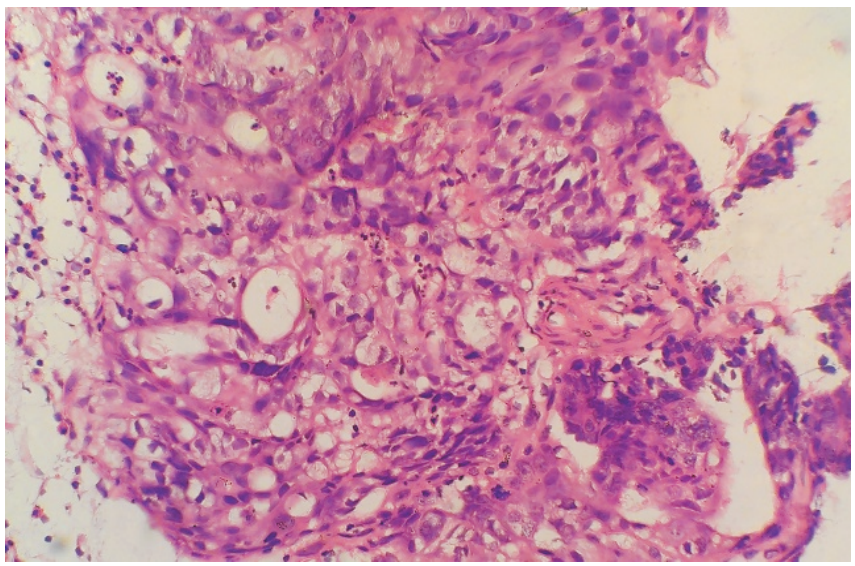

\section{CONCLUSION}

It was observed that endoscopic diagnoses of gastric lesions poorly correlated with those of histopathological diagnoses. $H$. pylori has a high prevalence in our region and is mostly associated with IM, CG and AG. As IM and AG are premalignant lesions, their early detection and intervention is essential. Endoscopic examination and biopsy is a convenient procedure for accurate objective assessment of patients with gastric symptoms. Endoscopy is incomplete without biopsy and histopathology is the gold standard for the diagnosis of endoscopically detected lesions. Endoscopic examination and histopathological examination of suspected gastric lesions should go parallelly and neither of them should be a substitute of each other. 


\section{REFERENCES}

1. Kreuning $J$ et al. Gastric and duodenal mucosa in 'healthy'individuals, Journal of Clinical Pathology, 1978, 31, 69-77.

2. Hopkins HH. Optical principles of endoscope. In: Berci G, ed. Endoscopy. 2nd ed. New York: Appleton Century Grafts, 1976: 3 - 26 .

3. Ofman JJ, Shaheen NJ, Desai AA, Moody B, Bozymski EM, Weinstein WM. The quality of care in Barrett's esophagus. Endoscopist and pathologist practices. Am J Gastroenterol. 2001; 96:876-81.

4. Warren JR, Marshall BJ. Unidentified curved bacilli on gastric epithelium in active chronic gastritis. Lancet 1983; 1. 1273-5.

5. Versalovic J. Helicobacter pylori: Pathology and Diagnostic Strategies 2003. Am J. Clin Pathol, 119: 40312.

6. Vartanian RK, Leung JK, Davis JE et al. A novel Alcian yellow-toluidine blue (Leung) stain for Helicobacter species: comparison with standard stains, a cost-effectiveness analysis and supplemental utilities. Mod Pathol 1998, 11:728.

7. Guy CD, Giltman LI, Varman VA. Comparison of histochemical stains for the diagnosis of Helicobacter pylori. Am J Clin Pathol 1997; 107:473.
8. Chan WY, Hui PK, Leung KM et al. Coccoid forms of Helicobacter pylori in the human stomach. Am J Clin Pathol 1994; 102:5037.

9. Levy N, StermerE, Boss JM. Accuracy of endoscopy in the diagnosis of inflamed gastric and duodenal mucosa; sr JMed Sci. 1985 Jul; 21(7):564-8.

10. Hecker R, Fitch R, Rowland R. The Value of endoscopy and biopsy in the diagnosis of gastric carcinoma, Med J Aust. 1975 Sep 20:2(12):472-4.

11. Muller LB, Fagundes RB, Moraes CC, Rampazzo A. Prevalence of Helicobacter pylori infection and gastric cancer precursor lesions in patients with dyspepsia. Arq Gastroenterol. 2007 Apr-Jun;44(2):93-8.

12. Joo YE, Park HK, Myung DS, Baik GH, Shin JE, Seo GS, Kim GH, Kim HU, Kim HY, Cho SI, Kim N. Prevalence and risk factors of atrophic gastritis and intestinal metaplasia: a nationwide multicenter prospective study in Korea. Gut Liver. 2013 May;7(3):303-10. doi: 10.5009/gnl.2013.7.3.303. Epub 2013 May 13.

13. Calabrese $C$ et al. Correlation between endoscopic features of gastric antrum, histology and Helicobacter pylori infection in adults, Ital JGastroenterol Hepatol. 1999Jun-Jul;31(5):359-65.

14. Redéen S, Petersson F, Jönsson KA, Borch K. Relationship of gastroscopic features to histological findings in gastritis and Helicobacter pylori infection in a general population sample. Endoscopy. 2003 Nov;35(11):946-50.

\section{Universal College of Medical Sciences and Teaching Hospital Our Academic Programmes}

$>$ MBBS

$>\mathrm{BDS}$

> MD/MS (Surgery, Paediatrics, Orthopaedics, Radiology, Anesthesia, Psychiatry, Medicine, Gynecology, ENT, Dermatology, Ophthalmology, Pathology, Microbiology, Anatomy, Pharmacology, MDGP)

> MDS (Oral \& Maxillofacial Surgery, Periodontics, Conserative Dentistry \& Endodontics, Orthodontics \& Dentofacial Orthopedics, Prosthodontics \& Maxillofacial Prosthetics)

$>$ Bsc. Nursing

$>$ Bachelor in Nursing (B.N.)

$>$ Bachelor in Pharmacy (B.Pharma)

$>$ Bachelor in Medical Laboratory Technology (BMLT) 